\title{
LETTERS
}

\section{An author responds to "Most important risk factor missing from COPD score"}

My coauthors and I thank Dr. Don Eby for his interest in our article. ${ }^{1,2}$

I have 37 years of experience working in a large emergency department and am very familiar with the complexities of making admission decisions. In our paper, my coauthors and I go to great lengths to indicate that medical risk of a poor outcome is only 1 factor to consider, along with many others. The following quotation is taken from the article's Interpretation section:

Many nonmedical factors are important in the decision to admit a patient, such as support at home or availability of early follow-up. We see OCRS [Ottawa COPD (chronic obstructive pulmonary disease) Risk Scale] as an important tool to help physicians gauge the medical risk for their patients with COPD, while they determine the need for admission or early follow-up. ${ }^{2}$

\section{Ian G. Stiell MD MSc}

Physician and distinguished professor, The Ottawa Hospital, Ottawa, Ont.

- Cite as: CMAJ 2019 April 1;191:E371. doi: 10.1503/cmaj.71712

\section{References}

1. Eby D. Most important risk factor missing from COPD score [letter]. CMAJ 2019;191:E370.

2. Stiell IG, Perry JJ, Clement CM, et al. Clinical validation of a risk scale for serious outcomes among patients with chronic obstructive pulmonary disease managed in the emergency department. CMAJ 2018;190:E1406-13.

Competing interests: None declared. 